\title{
Users' Perceptions on Drinking Water Quality and Household Water Treatment and Storage in Small Towns in Northwestern Tanzania
}

\author{
Zacharia S. Masanyiwa1 ${ }^{*}$, Innocent J. E. Zilihona1, Benedict M. Kilobe² \\ ${ }^{1}$ Institute of Rural Development Planning, Dodoma, Tanzania \\ ${ }^{2}$ Institute of Rural Development Planning, Lake Zone Training Centre, Mwanza, Tanzania \\ Email: ${ }^{\star}$ zmasanyiwa@irdp.ac.tz
}

How to cite this paper: Masanyiwa, Z.S., Zilihona, I.J.E. and Kilobe, B.M. (2019) Users' Perceptions on Drinking Water Quality and Household Water Treatment and Storage in Small Towns in Northwestern Tanzania. Open Journal of Social Sciences, 7, 28-42.

https://doi.org/10.4236/jss.2019.71003

Received: May 17, 2018

Accepted: January 6, 2019

Published: January 9, 2019

Copyright $\odot 2019$ by author(s) and Scientific Research Publishing Inc. This work is licensed under the Creative Commons Attribution International License (CC BY 4.0).

http://creativecommons.org/licenses/by/4.0/

(c) (i) Open Access

\begin{abstract}
Despite recent progress in increasing the world's population with sustainable access to safe drinking water, hundreds of millions still rely on unimproved sources. To improve the quality of drinking water, various household water treatment and safe storage methods have been developed, adopted and promoted as alternative interventions. However, there is paucity of information regarding drinking water quality and prevalence of HWTS practices especially from the users' perspectives in Tanzania. This paper examines users' perceptions on drinking water quality and household water treatment and storage practices in the selected towns of Misungwi, Magu and Lamadi in Northwestern Tanzania. The specific objectives of the study were 1) to examine users' perceptions on drinking water quality, and 2) to identify household water treatment and storage methods used in the study towns. The paper is based on empirical primary and secondary data collected from 417 households, through survey, key informant interviews, observation and documentary review, and analysed for descriptive statistics, chi-square tests and qualitative content analysis. The study found that water supply coverage in the study towns was generally low. Households drew water from various sources, including ones which were not suitable for drinking. This necessitated households to improve the quality of their drinking water through HWTS practices. Although a combination of adequate and inadequate treatment methods was used to improve water quality and aesthetics, prevalence of HWT practices was generally low. Similarly, safe storage was rarely practiced. Therefore, interventions aimed at improving access to domestic water supply should also incorporate elements of water treatment and safe storage at the point of use to contribute to improved health outcomes.
\end{abstract}




\section{Keywords}

Drinking Water, Water Quality, Users' Perceptions, Household Water Treatment, Water Storage

\section{Introduction}

Water is essential to sustain life, and adequate, safe and accessible supply must be available to all [1]. Despite recent progress in increasing the world's population with sustainable access to safe drinking water, thus, meeting the Millennium Development Goal 7 target of halving the proportion of the world's population without sustainable access to safe water [2] [3] [4], hundreds of millions more rely on improved water sources that are nevertheless subject to frequent and extensive microbial contamination [2]. While piped water supply is an important long-term goal for many developing countries, including Tanzania, this remains elusive in many settings. The World Health Organisation shows that nearly 663 million people in the world, mostly in sub-Saharan Africa, still lack access to safe and clean drinking water [4]. Unsafe drinking water along with poor sanitation and hygiene, accounts for nearly $10 \%$ of the total burden of diseases worldwide [2]. Diseases that can be transmitted by the waterborne route include cholera, typhoid fever, amoebic and bacillary dysentery and other diarrheal diseases [5] [6]. Recent estimates show that some 842,000 people die each year from diarrhoea because of unsafe drinking water, sanitation and hygiene [4]. In Tanzania, it is estimated that more than 20,000 children die each year due to diarrhea and other water-related diseases [6].

Safe drinking water is defined as one that does not represent any significant risk to health over a lifetime of consumption, including different sensitivities that may occur between life stages [1] [7]. In other words, this entails water having acceptable quality in terms of its physical, chemical and bacteriological parameters so that it can be safely used for drinking [8]. In accessing the quality of drinking water, users rely principally upon their senses. Microbial, chemical and physical water constituents may affect the appearance, odour or taste of water [1] [9] [10]. Although these substances may have no direct health effects, water which is highly turbid and colored or has some objectionable taste or odour may be regarded by consumers as unsafe [1] [7]. Taste and odour rely on close physiological processes and the originating stimuli can derive from the same substance. The interaction among taste, odour and colour can also be due to psychological factors, as users expect the sensorial information to be consistent. Consequently, the importance given by water users to drinking water organoleptics (i.e. sensorial information from taste, odour, colour and turbidity) can influence users' perception, satisfaction, willingness to pay and selection of water sources [11]. It is, therefore, important to understand users' perceptions on the drinking water quality to help improve water supply services and satisfaction. 
Where water sources are likely to be contaminated, drinking water must be treated to improve its quality and prevent waterborne diseases. In the absence of functioning centralized water treatment systems, this responsibility falls to consumers by default [5]. In fact, as Rosa and Clasen note, even tap water supplied to urban dwellers throughout the developing world is often uncertain of microbiological quality due to inadequate treatment or is subject to seasonal or other periodic incursions of microbial contaminants because of failures in the distribution system [2]. Water quality is further compromised by waterborne pathogens during collection, transportation and storage at household level [3]. To improve the microbiological quality of drinking water and prevent water borne diseases, simple and effective household water treatment and safe storage methods are considered as alternative interventions [1] [2] [3] [7].

The World Health Organisation defines household water treatment methods as a range of devices or methods employed for the purposes of treating water in the home or at the point of use in other settings. These are also known as point-of-use or point-of-entry water treatment technologies. They comprise a range of options that enable individuals and communities to treat collected water or contaminated piped water to remove or inactivate microbial pathogens [7]. Many of these methods are coupled with safe storage of the treated water to preclude or minimize contamination after household treatment, thus, the concept of household water treatment and safe storage (HWTS).

Household water treatment and safe storage have been shown to significantly improve water quality and reduce waterborne infectious disease risks [1] [7]. Evidence shows that treating water at household level or other point of use reduces the risk of waterborne diseases arising from recontamination during collection, transport and use in the home. It is argued that HWTS reduces exposure to diarrheagenic microbes and delivers the health gains of drinking safe water at lower cost for those not yet served by reliable piped water [2] [4] [12]. The World Health Organisation shows that HWTS lets people take responsibility for their own water security by treating and safely storing water themselves [13]. HWTS is also viewed as a simple, self-reliant, local, user friendly and cost-effective way which can be adopted immediately in the homes of poor and vulnerable families to improve their drinking-water quality to significantly improve health and prevent diseases [13] [14]. Depending on the method, treatment at the household level can remove, kill, or inactivate most microbial pathogens.

Some of the HWTS methods, such as boiling, have for many years been used by households to treat their water before drinking it, although have recently been heavily promoted by governments, health-care providers and others. Others, such as straining through a cloth or allowing it stand and settle, have little microbiological efficacy except in special cases and mainly practiced to improve aesthetics [1] [2] [7] [12]. Studies also show that HWTS adds to the time and expense required of consumers [5]. Similarly, HWTS does not improve access to 
water supplies or increase the quantity of water used, which are necessary for optimal health, domestic hygiene and economic benefits [2].

In Tanzania, despite the widespread promotion of HWTS, there is paucity of information regarding drinking water quality and prevalence of HWTS practices especially from the users' perspectives. Recent empirical studies have mainly focused on the efficacy of individual HWTS methods and practices, such as chlorination [12] and use of purification tablets [3]. A 2009 national survey on HWTS established low level of HWTS practices in Tanzania: only 50\% of the surveyed households used some measures to improve water safety at home [5]. Thus, users' perceptions on drinking water quality and prevalence of HWTS especially in areas with critical shortage of domestic water supply warrant investigation. This study contributes to the existing small body of academic literature by examining users' perceptions on drinking water quality and household water treatment and storage practices in the selected towns of Misungwi, Magu and Lamadi along the shores of Lake Victoria in Northwestern Tanzania. The specific objectives of the study are twofold. 1) to examine users' perceptions on drinking water quality, and 2) to identify household water treatment and storage methods used in the study towns. The remainder of the paper is structured as follows. The next section positions the study into the broader theoretical context by explaining the theoretical framework used. This is followed by a description of the study area and methodology, including the design, sample size and sampling procedures, data types, sources and collection methods, and how the collected data were analysed. Then, we present and discuss the findings of the study. In the last section, we draw the key conclusions and recommendations emerging from the study.

\section{Theoretical Framework}

Theoretically, the study draws on the users' perspective which posits that people shape and reshape their situation and interact with their environment using their skills, knowledge and experience [15]. Campilan describes users as "actors, who far from being receivers of services, are dynamic individuals and groups with ability to perform a range of activities along the service delivery chain, and demonstrate informed decision making" [16]. In the context of drinking water supply, participation of users in the design, operation and maintenance of service infrastructure and HWTS is regarded as important [17] [18] [19]. Thus, this perspective is relevant in this study because it is used to assess whether and how indeed water users in the study areas take responsibility to improve their drinking water quality by treating and safely storing it. This is important because it helps to focus the study to the "perceived" quality of drinking water from the users' perspectives as opposed to the "technical quality". Further, the household is used as the unit of analysis because it is an arena where much of daily takes place and the centre of processes that determine the welfare of individual members. It is within this arena of everyday life, this basic unit of social organization. 
Those activities to provide for people's basic needs, including drinking water supply, are undertaken [15] [20] [21].

\section{Materials and Methods}

This paper is based on empirical data collected through a survey in the towns of Misungwi, Magu and Lamadi along the shores of Lake Victoria in Northwestern Tanzania. The main source of domestic water supply in the study towns is Lake Victoria. However, the towns experience acute shortages of domestic water supply mainly due to inadequate water infrastructure, frequent breakdowns because of old depilated infrastructure and lack of water treatment plants [22] [23] [24]. Thus, if people in these towns want clean drinking water, they must make efforts to purify it in their households.

A cross-sectional design, which entailed collecting data at a single point in time [25], was employed in this study. Primary and secondary data of quantitative and qualitative nature were collected to adequately address the study objectives. Primary data were gathered from households and officials within the water utilities and district councils in the area whereas secondary data were obtained from relevant documents at district councils and water utilities to complement the primary data.

A combination of purposive and random sampling techniques was used. Purposive sampling was used to select 14 villages and mitaa within the urban centres of the study towns: 5 villages in Misungwi, 5 mitaa in Magu and 4 villages in Lamadi. Most of the selected villages and mitaa were located along the water supply network from the water intakes to town centres and distribution tanks. Simple random sampling technique was further used to select households within each village/mtaa for the survey because it provides equal chance for households to be involved in the study, thus, reducing biasness and enhancing reliability of the findings [26].

Since the population of the study towns was large to have an optimum sample size which is manageable and meets the requirements of efficiency, representativeness, reliability and flexibility [25], a sample size calculator using the Creative Research System was used to determine the sample size. A confidence interval of 5 was used because the higher the confidence interval the higher the accuracy of the answers to be picked and $95 \%$ confidence level was used as is commonly used by researchers [27]. Based on this, a sample size of 417 households was selected (Table 1). From each village or mtaa, a minimum of 30 households

Table 1. Household sample size.

\begin{tabular}{cccc}
\hline Town & Total population & Number of households & Sample size \\
\hline Misungwi & 30,728 & 5179 & 169 \\
Magu & 23,822 & 4326 & 121 \\
Lamadi & 22,062 & 5391 & 127 \\
Total & 76,612 & 14,896 & 417 \\
\hline
\end{tabular}


were surveyed, which is a reasonable sample for statistical analysis and comparison across the villages/mitaa [28].

As indicated earlier, this study used mixed methods of data collection from multiple sources of evidence to get deeper insights and contribute to reliability and validity of the findings. A structured questionnaire with closed and open-ended questions was used for the household survey. The questionnaire aimed at collecting data on household socio-economic characteristics, type of drinking water sources, users' perceptions on drinking water quality and household water treatment and storage (HWTS) practices. Key informant interviews were organized with ward and mtaa/village leaders, district council staff and water utilities officials. Non-participant observation, which involved visiting and observing water sources and intakes, was also used.

Quantitative data collected using the questionnaire survey were entered into the Statistical Package for Social Sciences (SPSS) to make them amenable for analysis. Most of the household survey data were analysed for descriptive statistics such as frequencies and means. Chi-square tests were used to establish whether there were significant variations across the three towns on a number of variables. The qualitative data obtained from observation, key informant interviews and the open-ended questions in the questionnaire were transcribed and analysed using qualitative content analysis technique, which involved transcribing and reading through the field notes and transcripts to identify key themes and patterns relevant to the study objectives and questions. Presentation and discussion of the findings weaves together the quantitative and qualitative data because quantitative and qualitative data are mutually dependent and tend to complement each other.

\section{Results and Discussion}

\subsection{Drinking Water Sources}

The survey findings show that, overall, about two thirds of the households collected drinking water from protected dug wells (34\%) and public taps/stand pipes $(31 \%)$. A significantly $(p=0.000)$ larger proportion of households in $\mathrm{Mi}$ sungwi $(62 \%)$ than in other towns obtained drinking water from protected dug wells. The main sources of drinking water in Magu were public taps, stand pipes or communal taps (34\%) and protected dug wells (31\%). In Lamadi, close to two thirds of households (61\%) depended on public taps, stand pipes or communal taps, which was significantly $(p=0.000)$ larger than in other towns. Household connections were generally few and accounted for only $7 \%, 10 \%$ and $4 \%$ in Misungwi, Magu and Lamadi, respectively. Water vendors were also an important source of drinking water especially in Magu and Lamadi (5\% each) as shown in Table 2. This shows that water supply coverage in the study towns is low as reflected the low proportions of household connections and public stand pipes [29]. Consequently, households drew water from various sources, some of which were not suitable for drinking and are subject to microbial contamination. This 
Table 2. Main sources of drinking water for the household $(n=417)$.

\begin{tabular}{cccccc}
\hline Source & Misungwi & Magu & Lamadi & All & $\begin{array}{c}\text { Chi-square } \\
\text { value }\end{array}$ \\
\hline $\begin{array}{c}\text { Piped into the house } \\
\text { Piped to yard/plot }\end{array}$ & $2(1.2)$ & $3(2.5)$ & $0(0.0)$ & $5(1.2)$ & \\
$\begin{array}{c}\text { Public tap/stand } \\
\text { pipe/communal tap }\end{array}$ & $13(7.7)$ & $41(33.9)$ & $78(61.4)$ & $132(31.7)$ & \\
Borehole & $16(9.5)$ & $0(0.0)$ & $1(0.8)$ & $17(4.1)$ & \\
Protected dug well & $105(62.1)$ & $37(30.6)$ & $1(0.8)$ & $143(34.3)$ & \\
Unprotected dug well & $11(6.5)$ & $3(2.5)$ & $3(2.4)$ & $17(4.1)$ & $\chi^{2}=209.811$ \\
Unprotected spring & $7(4.1)$ & $11(9.1)$ & $19(15.0)$ & $37(8.9)$ & $p=0.000$ \\
Protected spring & $1(0.6)$ & $0(0.0)$ & $1(0.8)$ & $2(0.5)$ & \\
Rain water collection/harvesting & $1(0.6)$ & $0(0.0)$ & $0(0.0)$ & $1(0.2)$ & \\
Lake/river/stream & $1(0.6)$ & $9(7.4)$ & $13(10.2)$ & $23(5.5)$ & \\
Water tanker & $0(0.0)$ & $2(1.7)$ & $0(0.0)$ & $2(0.5)$ & \\
Other sources & $2(1.2)$ & $6(5.0)$ & $6(4.7)$ & $14(3.4)$ & \\
\hline
\end{tabular}

Figures in brackets are percents.

necessitates households to improve the quality of their drinking water mainly through HWTS. Indeed, as others have argued, where drinking water is collected from unprotected sources and in the absence of functioning centralized water treatment systems, this responsibility falls to consumers [5]. According to the World Health Organisation, water users' actions may help to ensure the safety of the water they consume and may also contribute to improvement or contamination of the water consumed by others. They have the responsibility for ensuring that their actions do not have an adverse impact on water quality [7].

To understand the suitability of water from these sources for drinking, the sources were classified as either "improved" or "unimproved". WHO and UNICEF define improved drinking water sources that by nature of their construction or through active intervention are protected from contamination, particularly faecal matter. These comprise piped household water connections inside the users' dwelling, plot or yard; public taps or stand pipes; tube wells or boreholes; protected dug wells; protected springs and rain water collection [6]. This definition is also used by the Tanzania national water policy [30], thus, was adopted in this study.

Overall, more than three quarters of households (77\%) used improved drinking water sources and about one quarter (23\%) depended on unimproved sources. Significantly $(p=0.000)$ larger majority of households in Misungwi (87\%) than their counterparts in Magu (74\%) and Lamadi (67\%) collected drinking water from improved sources. One in every three households in Lamadi (33\%), just over one quarter in Magu (26\%) and slightly above one tenth in Misungwi (13\%) relied on unimproved sources (Table 3). It was further estab- 
lished from the water utilities that water supply coverage was 35\%, 31\% and 23\% in Lamadi, Misungwi and Magu, respectively. There were 1263 household connections in Misungwi, 1068 in Magu and 102 in Lamadi. Generally, water supply coverage in the study towns was below the national average for urban areas of $86 \%$ in Tanzania [31]. This means that a substantial proportion of households which relied on unimproved sources were likely to be consuming water which is contaminated, hence, susceptible to water related diseases [6] [32] [33]. Impliedly, these findings suggest that water users in the study areas have a responsibility to improve their drinking water quality by treating and safely storing in their homes, as discussed in section 4.3 of this paper. This could help the intransigent problem of safe, clean water in the study towns [14].

\subsection{Users' Perceptions of Drinking Water Quality}

Water quality can be defined by three broad categories: microbiological, chemical and physical/aesthetic attributes [14]. In this study, the quality of drinking water was measured by using perceived impression of quality of water. The focus was on the "perceived quality" from the users' perspectives as opposed to "technical quality". Overall, more than half of the households (57\%) indicated that their drinking water was "clean": 53\%, 60\% and 60\% in Misungwi, Magu and Lamadi, respectively. Another one quarter (25\%) reported that water had "some particles", with significantly $(p=0.000)$ higher proportions in Magu $(32 \%)$ and Lamadi (32\%) than in Misungwi (15\%). About 6\% of households with about one in ten in Misungwi (10\%) indicated that water had "some taste", although this was significantly $(p=0.000)$ low in Magu (3\%) and Lamadi (3\%). Few households (4\%) with similar proportions across the three towns reported their drinking water having sand (Table 4).

Table 3. Classification of drinking water sources for the household $(n=417)$.

\begin{tabular}{cccccc}
\hline Category of source & Misungwi & Magu & Lamadi & All & Chi-square value \\
\hline Improved source & $147(87.0)$ & $90(74.4)$ & $85(66.9)$ & $322(77.2)$ & $\chi^{2}=17.356$ \\
Unimproved source & $22(13.0)$ & $31(25.6)$ & $42(33.1)$ & $95(22.8)$ & $\begin{array}{c}\text { df }=0.000 \\
\text { Un }\end{array}$ \\
\hline
\end{tabular}

Figures in brackets are percents.

Table 4. Perceived impression of water quality by town $(n=417)$.

\begin{tabular}{cccccc}
\hline Perceived quality & Misungwi & Magu & Lamadi & All & Chi-square value \\
\hline Clean & $89(52.7)$ & $73(60.3)$ & $76(59.8)$ & $238(57.1)$ & \\
Has sand in it & $7(4.1)$ & $5(4.1)$ & $5(3.9)$ & $17(4.1)$ & \\
Has small particles & $26(15.4)$ & $39(32.2)$ & $40(31.5)$ & $105(25.2)$ & $\chi^{2}=56.631$ \\
Has some taste & $16(9.5)$ & $3(2.5)$ & $4(3.1)$ & $23(5.5)$ & $\mathrm{df}=10$ \\
Has odour & $7(4.1)$ & $1(0.8)$ & $0(0.0)$ & $8(1.9)$ & $p .000$ \\
Others & $24(14.2)$ & $0(0.0)$ & $2(1.6)$ & $26(6.2)$ & \\
\hline
\end{tabular}

Figures in brackets are percents. 
Table 5. Perceived impression of water quality by water source $(n=417)$.

\begin{tabular}{ccccc}
\hline Perceived quality & Improved source & Unimproved source & All & Chi-square value \\
\hline Clean & $213(66.1)$ & $25(26.3)$ & $238(57.1)$ & \\
Has sand in it & $1(0.3)$ & $16(16.8)$ & $17(4.1)$ & \\
Has small particles & $55(17.1)$ & $50(52.6)$ & $105(25.2)$ & $\chi^{2}=115.062$ \\
Has some taste & $22(6.8)$ & $1(1.1)$ & $23(5.5)$ & $\mathrm{df}=5$ \\
Has odour & $8(2.5)$ & $0(0.0)$ & $8(1.9)$ & \\
Others & $23(7.1)$ & $3(3.2)$ & $26(6.2)$ & \\
\hline
\end{tabular}

Figures in brackets are percents.

The findings in Table 5 further show that households using improved sources (66\%) were significantly ( $p=0.000)$ more likely to perceive their drinking water as "clean" compared to those that used unimproved sources (26\%). On contrast, more than half of households collecting drinking water from unimproved sources $(53 \%)$ opined that their drinking water had some particles and another $17 \%$ in the same category reported that their drinking water had sand. About $7 \%$ and $3 \%$ of those using improved sources complained of their water having some taste and odour. As WHO points out, changes in the normal appearance, colour or taste of drinking water supply, presence of sand or particles may signal changes in the quality of water source because of pollution, deficiencies in the treatment processes or distribution [1] [7]. Thus, our findings point to the fact that the quality of drinking water in the study towns was not assured. Consequently, households that relied on unimproved sources of drinking water were at risk of drinking contaminated water, which must be treated and safely stored to make it safe for drinking. This reflects WHO's position that in households using non-piped water supplies, appropriate efforts are needed to ensure safe collection, storage and treatment of their drinking-water [7]. We turn to this point in the next sub-section.

\subsection{Household Water Treatment and Storage Practices}

Data on HWT practices were derived from two core questions in the household survey. 1) Do you treat drinking water to make it safer at your household? And if the answer was affirmative, then the second question was asked 2) Which is the most common method for treating drinking water used by your household? Similar questions are used in national surveys by WHO/UNICEF Joint Monitoring Program (JMP) [2]. The findings show that over half of the households (53\%), with a significantly higher proportion in Lamadi $(80 \%)$ than in other towns reported that they did treat their drinking water before consumption. However, more than three quarters of households in Misungwi (78\%), about one third in Magu (32\%) and just over one fifth in Lamadi (21\%) did not treat their drinking water. Comparatively, a significantly $(p=0.000)$ larger proportion of households collecting water from unimproved sources $(72 \%)$ were treating their water whereas less than half of those obtaining water from improved sources did 
so (Table 6). This could possibly be due to users' perception that tap water is generally safe [11]. But, this perception may pose health risks to water users because even tap water is often uncertain of microbiological quality due to inadequate treatment or contamination during collection, transportation and storage [2] [11] [34].

Generally, prevalence of HWT in the study towns is low and does not significantly differ from what was observed in the national survey in 2009 , which was $50 \%$ [31]. Thus, a substantial proportion of households used drinking water which was likely to be contaminated. Of particular concern was the $28 \%$ of households collecting drinking water from unimproved sources, yet did not treat it (Table 6). This could contribute to water related diseases. Discussions with the District Medical Officers in the three towns revealed that water borne diseases especially diarrhoea, typhoid and worms were among the top ten diseases in these areas. Elsewhere, a comparative study in low and middle-income countries reports as high as $90 \%$ of households practicing HWT in countries like Indonesia, Mongolia and Vietnam, but low prevalence of less than $10 \%$ in most African countries [2].

Boiling was the predominant HWT method used by over two thirds of the surveyed households $(68 \%)$ reporting the practice, with higher proportions in Misungwi and Magu (73\%, each) than in Lamadi (61\%). Other HWT practices were comparatively less common. Straining through a cloth (overall, 13\%) was reported by $27 \%, 9 \%$ and $12 \%$ of the households in Misungwi, Magu and Lamadi, respectively. Another $9 \%$ of households were "letting water to stand or settle", mostly in Lamadi (27\%) than in other towns. The use of water guard or chlorine was reported by $7 \%$ of the households, mostly in Lamadi (10\%) and Magu (6\%), but none in Misungwi. Use of filters was only reported in Magu (7\%), but not in other towns. There was no significant association $(p=0.549)$ between HWT method used and the type of drinking water source (Table 7). This shows that households in the study towns used a variety of drinking water treatment methods regardless of the water source.

However, the efficacy of some of these methods in ensuring drinking water

Table 6. Treat drinking water to make it safer by town and water source $(\mathrm{n}=417)$.

\begin{tabular}{ccccc}
\hline Category & Response & Yes & No & Chi-square value \\
\hline Misungwi & $37(21.9)$ & $132(78.1)$ & \\
District & Magu & $82(67.8)$ & $39(32.2)$ & $\chi^{2}=112.047$ \\
& Lamadi & $101(79.5)$ & $26(20.5)$ & $\begin{array}{c}\mathrm{df}=2 \\
p=0.000\end{array}$ \\
All & $220(52.8)$ & $197(47.2)$ & \\
Water source & Improved & $152(47.2)$ & $170(52.8)$ & $\chi^{2}=17.486$ \\
& Unimproved & $68(71.6)$ & $27(28.4)$ & $p=0.000$ \\
& All & $220(52.8)$ & $197(47.2)$ & $p$ \\
\hline
\end{tabular}

Figures in brackets are percents. 
safety is minimal as not all HWT methods are highly effective in reducing all classes of waterborne pathogens [7]. In fact, the JMP classifies HWT practices into adequate and inadequate. Adequate practices include boiling, chlorination, use of filters and solar disinfection whereas straining through a cloth and letting water stand and settle are regarded as inadequate practices [2]. Studies show that boiling is one of the most microbiologically effective HWT that has been heavily promoted by governments, health care providers and others because it inactivates viral, parasitic and bacterial pathogens [2] [7] [12]. Although the method is economically and environmentally unsustainable, and provides no residual protection, partly because water can easily be recontaminated after cooling [2] [5], its wide use shows how effective the method can be adopted. Chlorination, though used by only a small proportion of households, appears to be the safest, most effective and least expensive chemical disinfectant for point of use treatment [3] [5], but ineffective for inactivating some pathogens like oocysts of the waterborne protozoan [7]. Straining through a cloth and allowing water to stand and settle, although help to avoid the particles in the water, have little microbiological efficacy except in special cases and are mainly practiced to improve aesthetics [2] [5] [7]. Thus, careful consideration of the effectiveness of these methods is needed when choosing among these options.

The majority (88\%) of those treating their drinking water were doing it "always": $84 \%, 93 \%$ and $85 \%$ in Misungwi, Magu and Lamadi, respectively (Figure 1).

Table 7. Household water treatment methods $(n=220)$.

\begin{tabular}{cccccc}
\hline Treatment method & Misungwi & Magu & Lamadi & All & Chi-square value \\
\hline Boiling & $27(73.0)$ & $60(73.2)$ & $62(61.4)$ & $149(67.7)$ & \\
Adding water guard/chlorine & $0(0.0)$ & $5(6.1)$ & $10(9.9)$ & $15(6.8)$ & \\
Straining through a cloth & $10(27.0)$ & $7(8.5)$ & $12(11.9)$ & $29(13.2)$ & $\chi^{2}=40.114$ \\
df $=10$ \\
Using water filter (ceramic; sand etc) & $0(0.0)$ & $6(7.3)$ & $0(0.0)$ & $6(2.7)$ & $p=0.000$ \\
Letting it stand and settle & $0(0.0)$ & $2(2.4)$ & $17(16.8)$ & $19(8.6)$ & \\
Other methods & $0(0.0)$ & $2(2.4)$ & $0(0.0)$ & $2(0.9)$ & \\
\hline
\end{tabular}

Figures in brackets are percents.

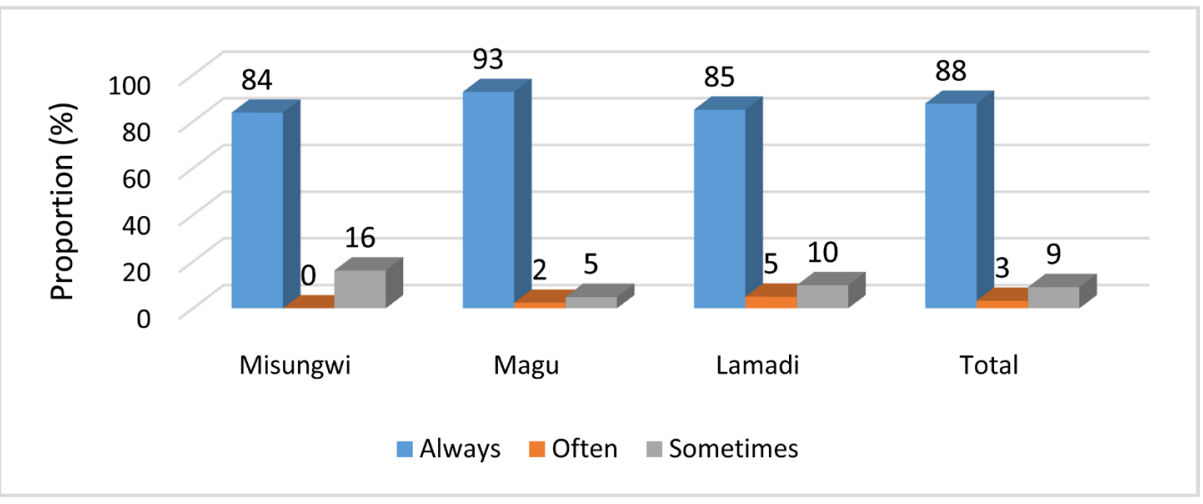

Figure 1. Frequency of treating drinking water. 
Others said that were "sometimes" treating drinking, water accounting for $16 \%$ in Misungwi, 10\% in Lamadi and 5\% in Magu. Few respondents did it "often", mostly in Lamadi (5\%) and Magu (2\%). This shows that most of the households that were treating their drinking knew the importance of doing so and, therefore, did it on daily basis. The findings suggest sustained use of HWT methods among most households practicing these methods, which was likely to contribute to improved health outcomes.

When asked about the reasons for treating drinking water, a significant majority of households (87\%), with almost all of them in Magu (96\%) and a large majority in Misungwi (87\%) and Lamadi (83\%) said they did so in order to kill germs. Few households, mostly in Lamadi (13\%) treated water to improve taste and another 5\% in Misungwi and 3\% in Lamadi to remove bad smell (Table 8). This shows that majority of those treating their drinking water were aware of the rationale of doing so, which was mainly to make it clean and safer for drinking by killing germs. The findings also reflect the fact that users treat their drinking water not only to improve quality, but also attach weight to water aesthetics [2].

In this study, household respondents were also asked about the type of container(s) used to store drinking water. This is important because safe storage helps to minimize contamination after household treatment [7]. Safe storage means the use of a protected container to keep water free from recontamination. The storage container should have a cover and a narrow mouth or tap/spigot which does not allow dipping of a cup [5] [14] [31]. The findings show that more than one third of the households (35\%), with high proportions in Misungwi (40\%) and Magu (38\%) than in Lamadi (25\%) used pails or buckets to store their drinking water. Another $31 \%$ of households used drums, with relatively higher proportions in Lamadi (41\%) than in Magu (31\%) and Misungwi (25\%). About $28 \%$ of households, with close to one third in Misungwi (32\%), over a quarter in Magu (26\%) and 24\% in Magu used clay pots (Table 9). This shows that almost all households stored their water in containers that did not have tight-fitting lids and narrow mouths to allow users to draw water by pouring [5]. This partly explains why a substantial proportion of households (42\%) used cups and another $22 \%$ were dipping their hands to draw water from the storage containers, implying that many did not use safe storage containers to store water in their homes. These practices could be a significant cause of drinking water contamination, thus, undermining the benefits of treating drinking water [34].

Table 8. Reasons for treating drinking water $(n=220)$.

\begin{tabular}{cccccc}
\hline Reason & Misungwi & Magu & Lamadi & All & Chi-square value \\
\hline Kill germs & $32(86.5)$ & $79(96.3)$ & $84(83.2)$ & $195(88.6)$ & \\
Remove bad smell & $2(5.4)$ & $2(2.4)$ & $3(3.0)$ & $7(3.2)$ & $\chi^{2}=17.411$ \\
Iff $=6$ \\
Improve taste & $1(2.7)$ & $1(1.2)$ & $13(12.9)$ & $15(6.8)$ & $p=0.008$ \\
Don't know & $2(5.4)$ & $0(0.0)$ & $1(1.0)$ & $3(1.4)$ &
\end{tabular}

Figures in brackets are percents. 
Table 9. Drinking water storage facilities $(n=417)$.

\begin{tabular}{cccccc}
\hline Container & Misungwi & Magu & Lamadi & All & Chi-square value \\
\hline Jerry can & $5(3.0)$ & $4(3.3)$ & $13(10.2)$ & $22(5.3)$ & \\
Clay pots & $54(32.0)$ & $32(26.4)$ & $30(23.6)$ & $116(27.8)$ & $\chi^{2}=22.468$ \\
Pails/buckets & $67(39.6)$ & $47(38.8)$ & $32(25.2)$ & $146(35.0)$ & $\mathrm{df}=8$ \\
Drums & $42(24.9)$ & $37(30.6)$ & $52(40.9)$ & $131(31.4)$ & $p=0.004$ \\
Other containers & $1(0.6)$ & $1(0.8)$ & $0(0.0)$ & $2(0.5)$ & \\
\hline
\end{tabular}

Figures in brackets are percents.

Studies in India and Malawi show that replacing unsafe storage vessels with safer ones can lead to lower rates of cholera transmission and less diarrhoea [5].

\section{Conclusion and Recommendations}

The overall conclusions emerging from this study were that there was low water supply coverage in the study towns in terms of household connections and public stand pipes. In turn, households drew water from various sources, including ones which were not suitable for drinking and were subject to microbial contamination. This necessitated households to improve the quality of their drinking water through HWTS practices. Although more than half of the households perceived their drinking water as clean, a substantial proportion was concerned with the taste, odour and presence of particles and sand in it. In other words, even water collected from improved sources was not perceived as safer water for drinking. Although households used a combination of adequate and inadequate treatment methods to improve both the quality and aesthetics of drinking water, prevalence of HWT practices in the study towns was generally low. Further, safe storage of water was also generally low. Therefore, it is recommended that whereas a number of government interventions aimed at improving access to domestic water supply in the study towns are being implemented, such interventions should also incorporate elements of water treatment and safe storage at the point of use in order to contribute to improved health outcomes. This can entail raising water users' knowledge on the importance of and appropriate HWTS methods.

\section{Conflicts of Interest}

The authors declare no conflicts of interest regarding the publication of this paper.

\section{References}

[1] World Health Organisation (2008) Guidelines for Drinking Water Quality. Third Edition Incorporating the First and Second Addenda. Volume 1: Recommendations. WHO, Geneva.

[2] Rosa, G. and Clasen, T. (2010) Estimating the Scope of Household Water Treatment in Low and Middle-Income Countries. American Journal of Tropical Medicine and 
Hygiene, 82, 289-300. https://doi.org/10.4269/ajtmh.2010.09-0382

[3] Kgabi, N., Mashauri, D. and Hamatui, N. (2014) Utilisation of Water Purification "Tablets" at Household Level in Namibia and Tanzania. Open Journal of Applied Sciences, 4, 560-566. https://doi.org/10.4236/ojapps.2014.414055

[4] World Health Organisation (2016) Drinking Water Fact Sheet. http://www.who.int/mediacentre/factsheets/fs391/en/

[5] Mintz, E., Bartram, J., Lochery, P. and Wegelin, M. (2001) Not Just a Drop in the Bucket: Expanding Access to Point of Use Water Treatment Systems. American Journal of Public Health, 91, 1565-1570. https://doi.org/10.2105/AJPH.91.10.1565

[6] United Nations Children's Fund and World Health Organisation (2012) Joint Monitoring Programme for Water Supply and Sanitation, Progress on Drinking Water and Sanitation. United Nations Children's Fund and World Health Organisation, Geneva.

[7] World Health Organisation (2011) Guidelines for Drinking Water Quality. 4th Edition, WHO, Geneva.

[8] Gadgil, A. (1998) Drinking Water in Developing Countries. Annual Review of Energy and Environment, 23, 253-256.

https://doi.org/10.1146/annurev.energy.23.1.253

[9] Gray, N.F. (2008) Drinking Water Quality. 2nd Edition, Cambridge University Press, Cambridge. https://doi.org/10.1017/CBO9780511805387

[10] Gray, N.F. (2011) Drinking Water Quality: Problems and Solutions. Cambridge University Press, Cambridge.

[11] Doria, M.F. (2010) Factors Influencing Public Perception of Drinking Water Quality. Water Policy, 12, 1-19. https://doi.org/10.2166/wp.2009.051

[12] Mohamed, H., Brown, J., Njee, R.M., Clasen, T. Malebo H.M. and Mbuligwe, S. (2015) Point of Use Chlorination of Turbid Water: Results from a Field Study in Tanzania. Journal of Water and Health, 13, 544-550. https://doi.org/10.2166/wh.2014.001

[13] World Health Organisation (2013) Household Water Treatment and Safe Storage. Manual for the Trainer. WHO, Geneva.

[14] Murcott, S. (2006) Implementation, Critical Factors and Challenges to Scale-Up of Household Drinking Water Treatment and Safe Storage Systems. Background Paper on Household Water Treatment and Safe Storage (HWTS) for the Electronic Conference May 12-22, 2006 Hosted by USAID/Hygiene Improvement Project (HIP).

[15] Niehof, A. and Price, L. (2001) Rural Livelihood Systems: A Conceptual Framework. Wageningen UPWARD Series on Rural Livelihoods No. 1.

[16] Campilan, D. (1996) The Changing Role of User in Sustainable Root Crop Agriculture: A Second Look at UPWARD's Second Phase. In: UPWARD, Ed., Into Action Research: Partnership in Asian Root Crop Research and Development, International Potato Centre, Los Banos, 193-201.

[17] World Bank (1994) World Development Report 1994: Infrastructure for Development. The World Bank, Washington DC.

[18] World Bank (2004) World Bank Development Report 2004: Making Services Better for Poor People. The World Bank, Washington DC.

[19] World Bank (2008) Decentralization in Client Countries. An Evaluation of World Bank Support, 1990-2000. World Bank Independent Evaluation Group, The World Bank, Washington DC.

[20] Masanyiwa, Z.S. (2014) Decision Making under the Tree: Gender Perspectives on 
Decentralization Reforms in Service Delivery in Rural Tanzania. PhD Thesis, Wageningen University, Wageningen.

[21] Mandara, C.G. (2014) What Policy Says and Practice Does: Gender, Household and Community in Rural Water Provision in Tanzania. PhD Thesis, Wageningen University, Wageningen.

[22] COWI (2015) Water Supply and Sanitation for Mwanza Town and Satellites: Technical Assistance for Preparation of Master Plan, Detailed Design and Tender Documents: Satellite Town Detailed Report: Misungwi Final Report.

[23] COWI (2015) Water Supply and Sanitation for Mwanza Town and Satellites: Technical Assistance for Preparation of Master Plan, Detailed Design and Tender Documents: Satellite Town Detailed Report: Magu Final Report.

[24] COWI (2015) Water Supply and Sanitation for Mwanza Town and Satellites: Technical Assistance for Preparation of Master Plan, Detailed Design and Tender Documents: Satellite Town Detailed Report: Lamadi Final Report.

[25] Kothari, C.R. (2009) Research Methodology: Methods and Techniques. Second Revised Edition, New Age International Publishers, New Delhi.

[26] Kumar, R. (2005) Research Methodology. A Step-by-Step Guide for Beginners. Second Edition, Sage Publications, London.

[27] Creative Systems (2012) Sample Size Calculator. https://www.surveysystem.com/sscalc.htm

[28] Grinnell, R.M. (2001) Social Work Research and Evaluation: Quantitative and Qualitative Approaches. 6th Edition, Thomson Brooks/Cole, Belmont.

[29] Masanyiwa, Z.S., Kilobe, B.M. and Mbasa, B.N. (2017) Household Access and Affordability to Pay for Domestic Water Supply Services in Small Towns in Tanzania: A Case of Selected Towns along the Shores of Lake Victoria. International Journal of Applied and Pure Science and Agriculture, 3, 45-58.

[30] United Republic of Tanzania (2002) National Water Policy. Ministry of Water and Livestock Development, Dar es Salaam.

[31] United Republic of Tanzania (2014) National Plan for Scaling Up Household Water Treatment and Safe Storage 2014-2019. Ministry of Health and Social Welfare, Dar es Salaam.

[32] Prasad, N. (2006) Privatization Results: Private Sector Participation in Water Services after 15 Years. Development Policy Review, 24, 669-692. https://doi.org/10.1111/j.1467-7679.2006.00353.x

[33] Masanyiwa, Z.S., Niehof, A. and Termeer, C.J.A.M. (2015) Users' Perspectives on Decentralized Rural Water Services in Rural Tanzania. Gender, Place and Culture: A Journal of Feminist Geography, 22, 920-936. https://doi.org/10.1080/0966369X.2014.917283

[34] Zilihona, I.J.E., Namwata, B.M.L. and Mandi, N. (2018) Baseline Survey for Water, Sanitation and Hygiene in 16 Regions of Tanzania Mainland. Compassion International Tanzania, Arusha Tanzania. 